\title{
El intelectual como partido: Dardo Cúneo y la experiencia de Acción Socialista
}

\author{
Carlos Miguel Herrera \\ Université de Cergy-Pontoise
}

El Partido Socialista Argentino construyó a lo largo de su historia una relación con los intelectuales no exenta de tensiones y conflictos. La fuerza nunca fue ajena, por cierto, a hombres con formación universitaria: quien se convierte rápidamente en su principal dirigente durante sus primeros treinta años, Juan B. Justo, no sólo era médico sino que había iniciado asimismo una carrera académica que lo lleva a la cátedra, debiendo abandonarla por las vicisitudes de la política. También habían pasado por la universidad otras figuras descollantes de esos primeros tiempos, como el ingeniero Germán Avé-Lallemant e incluso pronto aparece, a fines de 1894, un Centro socialista universitario como organización específica que se contará entre los fundadores del partido.

Pero existía desde el vamos cierta desconfianza hacia los intelectuales en tanto "grupo social". Esto queda expuesto también muy rápidamente, con los conflictos que llevan a abandonar el partido, a principios del siglo XX, al grupo de La Montaña que conformaban Leopoldo Lugones y, sobre todo, José Ingenieros, tal vez los primeros intelectuales socialistas en sentido estricto, tensiones que se repetirán en los años sucesivos con figuras menos importantes en el plano organizativo, como Manuel Ugarte o Roberto J. Payró. Ciertamente, un cambio importante se produce a inicios de los años 1930, cuando ingresan al partido un conjunto de intelectuales encabezados por Alejandro Korn, y entre los que destacan Arturo Orgaz, Carlos Sánchez Viamonte o Julio V. González, sin que los recelos desaparezcan sobre todo cuando los más jóvenes se inserten activamente en las estructuras partidarias. En efecto, estos intelectuales conservan una legitimidad que supera el marco partidario, por ejemplo no publicando sus obras en la editorial La Vanguardia sino en otras, conservando cátedras, etc. Al mismo tiempo, sus quehaceres militantes están ligados a sus destrezas intelectuales, como la comisión de cultura, la prensa, etc. 
La figura de Dardo Cúneo (1914-2011) puede ser abordada como un particular paradigma de intelectual socialista, en momentos en que el PS cumple su medio siglo de acción. Empero un conjunto de precisiones deben ser realizadas para abordar su caso, primero en lo que hace al contexto partidario en que se desarrolla su acción, luego sobre su propio estatuto de "intelectual".

En lo que respecta al primer tópico, su militancia se da en un período que hemos llamado de crisis permanente, abierto a partir de los años 1930 y que termina llevándolo a su dispersión definitiva en 1958 (Herrera, 2007). Como si la muerte de Justo hubiera significado también el fin del proyecto político que el fundador de La Vanguardia había diseñado a fines del siglo XIX, o al menos fracturado su coherencia interna. Una transformación profunda de aquella Argentina era sin duda la causa central, en la medida en que las hipótesis sobre las que se había construido el papel y el accionar del PS estaban desapareciendo de la vida nacional. Sin embargo, los signos de esta crisis partidaria no serán siempre claros de observar para los contemporáneos, ya que están enmarcados por algunos "éxitos", ante todo electorales, de corta duración, y que se revelan en definitiva sólo aparentes. ${ }^{1}$

Entre ambos extremos cronológicos de la crisis, se ubica el momento peronista del PS -momento central en todo el sentido de la palabra-, en que se desarrolla lo esencial de nuestro estudio. En efecto, contrariamente a una lectura establecida, la llegada del peronismo al poder no hace más que agudizar un conjunto de elementos que ya estaban presentes en la década previa, tornándose ciertamente más nítidos después de 1946, y estallando tras el derrocamiento del régimen justicialista. La novedosa corriente cívico-militar que se venía estructurando desde el Estado luego del golpe de 1943 comienza a hacer sentir sus efectos dentro del PS. No se trataba tan sólo de las persecuciones -bajo la forma de clausuras a su órgano partidario, la detención y el hostigamiento de los dirigentes socialistas, que llevaba a los principales líderes al autoexilio montevideano, antes de terminar sufriendo algu-

1. La abstención radical que se sucede a partir de 1931 había permitido al PS contar con la mayor representación parlamentaria de su historia. Al mismo tiempo, sus representantes obreros habian alcanzado la dirección del movimiento obrero organizado a nivel nacional, aunque se veían circundados a partir de 1936 por la dinámica del Partido Comunista. Si bien un nuevo desgajamiento, el del PSO, debilita electoralmente al PS en 1937-1938, el fin de la abstención radical no le impedirá, poco después, acentuar su peso en la Capital Federal, coronado por el triunfo electoral de 1942. Para entonces, el inicio de la Segunda Guerra Mundial le permitía estructurar el discurso político de la izquierda en un conjunto de organizaciones antifascistas. Pero las divisiones estallan ahora en el seno de su componente sindical, cuyo peso en la estructura partidaria había cambiado desde los años 1930. 
nos atentados mortales-, sino también de la fuerza de atracción que la acción del coronel Perón comenzaba a ejercer en una segunda línea de dirigentes socialistas, ligada sobre todo al movimiento sindical. De la denuncia de la usurpación de la obra legislativa del viejo partido se pasará pronto a la condena del "mal totalitario" que parecía instalarse en nuestras tierras tras ser derrotado en Europa, un giro que se agudiza con la nueva derrota que sufre el PS en las elecciones legislativas de 1948 y que confirman su desaparición de la representación nacional. Con todo, la linea antitotalitaria que termina de imponerse a finales de los años 1940, y que había llevado a formas inéditas del accionar socialista (como la abstención electoral o la ruptura total de contactos con las autoridades nacionales), genera tensiones y críticas, que el Gobierno no se priva de alentar con sus poderosos medios. Éstas se hacen más importantes en 1950, cuando, después del congreso partidario de noviembre de ese año, parecen cerrarse las posibilidades de renovación interna (Herrera, 2003).

También el estatuto intelectual de Cúneo exige algunas precisiones. Por lo pronto, no es un intelectual en el sentido general de la palabra, si se asocia la noción con una labor espiritual que da lugar a la intervención pública, pero con un grado central de autonomia. Su labor intelectual es su militancia, habiendo ingresado al partido antes de terminar la escuela secundaria. A diferencia de aquellos universitarios que entran también al PS a principios de los años 30, su legitimación como intelectual se desarrolla puertas adentro del partido, al menos en el período estudiado aquí. En definitiva, se acerca a la figura del intelectual orgánico, aunque la propia estructura abierta del PS impida encuadrarlo completamente en esta figura y, de hecho, otras áreas retienen su interés, ${ }^{2}$ y su actividad corresponde a la de un "publicista", una persona que literalmente vive de su pluma, sobre todo como periodista y ensayista, pero también como crítico y, más tarde, poeta. Cúneo se verá llamado a reflexionar sobre su propio estatuto, viéndose como un escritor que hace politica, lo que distinguía del "escritor político", porque de lo que se trataba era, como asevera, de ser escritor y político y a la vez. En verdad, tampoco se trataba de cualquier politica, sino de aquella en la que "el partido, más que partido resulte una misión, una cruzada", reivindicando, en esa veta, la figura del escritor irlandés George Bernard Shaw (Cúneo, 1950: 69). Si por un lado la actividad intelectual implica para él una jerarquización del político, la doctrina, al menos tal como se desarrolla dentro del socialismo, es un arma para la acción, como venía afirmándolo

2. Cúneo coordina la edición del teatro completo de Florencio Sánchez en 1941, publica un libro sobre Frank Brown en 1944, sin olvidar un celebrado ensayo sobre Sarmiento y Unamuno en 1948. Dedica también prólogos a obras de Francisco Bilbao, Walt Whitman o José Martí, sólo para referirse a su obra en el período aquí estudiado. 
en 1946. Y Cúneo integrará, a partir de los años 1940, las instancias dirigentes del PS, siendo particularmente activo en la prensa partidaria y en su organización cultural, amén de un escritor prolifico.

Más que en una obra propia, su significación como intelectual se encarna para nosotros en el proyecto político que dirigirá luego de su expulsión del PS en 1952, tras una serie de vicisitudes originadas a partir de una entrevista con el general Perón. Dicha experiencia no se resume la de un "intelectual" que dirige una organización socialista, sino en la de una agrupación que toma como su propio modo de intervención política el trabajo intelectual. Acción Socialista busca proyectar la labor intelectual a la organización política, bajo la forma del "fermentario", siguiendo el modelo de la Sociedad Fabiana en Inglaterra.

A mediados de 1952, Cúneo lanza un periódico socialista alternativo que pronto se transformará en organización. Menos conocido que aquel proceso que se desencadena con la salida del partido de Enrique Dickmann y que termina llevando a la fundación del Partido Socialista de la Revolución Nacional (PSRN) (Herrera, 2011), el proyecto de Acción Socialista, ${ }^{3}$ efimero y posiblemente menos ambicioso que aquél, representa sin embargo uno de los intentos más originales de dar respuesta a la cuestión de una fuerza alternativa al PS en esos años, sin buscar reproducir la forma partido, en un espacio dominado por el Partido Socialista y el Partido Comunista. La tentativa que trata de encarnar Cúneo se diferencia del proyecto del PSRN por dos características propias. Por un lado, se mantiene claramente a gran distancia con respecto al peronismo, imaginando una suerte de tercera vía entre éste y el PS. Por el otro, y tal vez más importante, intenta innovar en el tipo de construcción política posible, al menos en un primer momento. Como si cierta inteligencia táctica, unida a la relativa exigüidad de sus tropas, le permitiese observar que una nueva fuerza de izquierda no tiene posibilidades de existir de manera inmediata. Con un nombre menos conocido que el del viejo Dickmann para imantar disidencias, Cúneo buscará crear entonces un grupo político-intelectual que se asemeje al rol que jugaba la Sociedad Fabiana en Inglaterra de cara al Partido Laborista.

Dado que lo esencial de la historia de Acción Socialista se confunde con la figura de Cúneo, conviene detenerse en su itinerario partidario, que se desarrolla integralmente en el contexto de crisis que acabamos de puntualizar.

3. En lo que sigue, el nombre Acción Socialista se citará en itálicas cuando se haga referencia al periódico y simple cuando se refiera a la agrupación. 


\section{Un itinerario socialista}

Subrayar algunos elementos de su biografia política nos permitirá situar su posición en momentos en que se produce su salida del PS; hasta entonces, Cúneo aparecía como uno de los dirigentes más promisorios del socialismo argentino.

Como adelantáramos, Cúneo declarará haber ingresado al PS cuando todavía cursaba el colegio secundario, a fines de 1930, aunque su afiliación oficial corresponde a sus 18 años, en 1932. Poco después entra a militar en el ala izquierda del partido, particularmente activa en esos años, que buscaba organizarse por entonces acaudillada por Benito Marianetti desde Mendoza (Herrera, 2006). En la corta respuesta que Cúneo ofrece a la célebre encuesta de Claridad sobre la táctica del PS, señalaba que tres elementos debían llevar a un cambio en ella: la desocupación, el peligro de una guerra mundial y el fascismo. Hay que adaptar la táctica "al momento que nos toca vivir" y la lucha era ahora por la transformación social. El socialismo representaba un peligro inminente para la burguesía, y es por ello que ésta opta por la restricción de la libertad y el fraude electoral (Cúneo, 1933). Poco después, será testigo directo de esa radicalización de la lucha de clases en los años del fascismo europeo, cubriendo de manera ocasional para Crítica el inicio de la guerra civil española.

Cúneo colaboraba con el periódico del grupo Izquierda, que se editaba con el mismo nombre. Sin embargo, no sigue a los disidentes del ala izquierda, derrotados en el Congreso partidario de 1934, cuando, tras nuevas vicisitudes y alianzas, deciden organizar un nuevo partido, el Partido Socialista Obrero (PSO). Por el contrario, en 1938 Cúneo pasa a ocupar el cargo de secretario general de las Juventudes Socialistas, que conservará hasta 1941. Integra asimismo la redacción de La Vanguardia, dirigiendo el órgano de prensa de la juventud socialista, Futuro. A partir de 1941 es designado secretario de la estratégica "Comisión de prensa", un cargo que sólo abandonará durante el proceso que lleva a su expulsión. Para entonces, era ya miembro de la dirección de la Federación socialista capitalina, la más poderosa del Partido, pero que habia sufrido los coletazos de la reciente disidencia.

Su lugar dentro del PS se irá afirmando a partir de esa década de 1940, y su perfil se construye en torno a la figura de "escritor socialista". Amén de su actividad periodística, que había comenzado como redactor de La Razón en 1932 y había continuado en otros medios masivos (El Mundo, El Hogar), Cúneo se había transformado en un fecundo ensayista, con intereses que recorrian un amplio espectro cultural y literario. También era uno de los más activos docentes de la Escuela de Estudios Sociales del Partido. 
Y se puede considerar que al publicar en 1943 una biografia de Juan B. Justo, Cúneo está cumpliendo un paso más del cursus honorum socialista, sobre todo porque el prólogo es firmado por el principal dirigente partidario, Nicolás Repetto, que considera el libro, "relato fiel y sentido", como el "más completo y más serio de cuantos se han publicado hasta la fecha" (Repetto, 1943: 10). Este prólogo es para Repetto la ocasión para juzgar el estilo literario de Cúneo ("la frase muy corta", "la colocación del verbo al final") como eficaz. La biografia, tenuemente novelada, es saludada rápidamente como una referencia, ${ }^{4}$ lo que vale a Cúneo ser el editor, en 1947, del tomo VI de las Obras del maestro, bajo el título La realización del socialismo, y en cuyas páginas se reúnen los principales textos políticos de Justo. El autor del oportuno prólogo nos da un nuevo índice de la ubicación de Cúneo en las filas partidarias: está firmado por quien se está convirtiendo en el dirigente más relevante del PS por aquellos años, Américo Ghioldi, que no duda en calificar de "hermosa biografia" su libro sobre Justo. ${ }^{5}$ Otro folleto aparecido en ese mismo año, Juan B. Justo y la declaración de principios del Partido Socialista, que Cúneo publica después de haberlo profesado en el "Curso de iniciación" organizado en la Casa del Pueblo, nos permite entrever los acentos propios que contienen su visión del socialismo. En todo caso, Cúneo busca resaltar el carácter original, es decir, nacional y latinoamericano, del programa justista, que lo convierte en figura universal del socialismo. Un párrafo condensa en particular la interpretación dada:

La nacionalidad en esta América de raíz indígena y expresión hispana será realidad cuando las clases trabajadoras hayan ascendido, a través del socialismo, acompañando al socialismo y acompañándose de él, a la consciencia y ejercicio de sus intereses e ideales. La causa nacional, en nuestra América, es, fundamentalmente, causa del socialismo. (1947a: 33)

Se trata, en definitiva, como dice en otro trabajo contemporáneo, de una "visión y comprensión argentinas del socialismo" (1947b: 57). Entre ambas obras, Cúneo había desplegado también su incumbencia

4. Será reeditado, ampliado, una primera vez en 1956, con el título Juan B. Justo y las luchas sociales en la Argentina.

5. Por cierto, Ghioldi intenta vincular la obra de Justo con el "dificil momento" que está viviendo el país bajo el peronismo, y concluye que las ideas del "preclaro apóstol del movimiento obrero", preservan "de las falacias que rondan a la conciencia popular; de las falacias místicas y declamadoras, de las falacias autoritarias, de las falacias sobre conquistas súbitas que no dejan en el pueblo ni gérmenes de acción propia que es, en definitiva, el móvil primero y último de la democracia y el socialismo" (Ghioldi, 1947: 18). 
de historiador en torno a su dominio de intervención por excelencia, la prensa, publicando en 1945 una historia sobre El primer periodismo obrero y socialista. Poco después, le cabe a él el honor de ser prologuista, y nada menos que de Jacinto Oddone, para su Gremialismo proletario, aparecido en 1949.

Ya desde los años 1930 sus principales referentes dentro del partido son Alfredo L. Palacios y, todavía en mayor medida, Mario Bravo, sin duda el dirigente socialista que Cúneo más admiraba -"Americano y argentino, Bravo comprendió al socialismo como la lucha por la liberación de los hombres, que es la liberación de las patrias sometidas, lucha por la liberación de las clases esclavizadas"-, muerto en marzo de 1944. Bravo, que ha unido al revolucionario, al estudioso y al artista (1950: 10, 13), aparece para Cúneo como su modelo.

Cúneo no es, por cierto, un teórico del socialismo, que ofrezca una interpretación original o vigorosa de su doctrina, sino más bien un divulgador, un mediador a través de su elegante pluma. Entre los autores que Cúneo moviliza por entonces encontramos los nombres de Jean Jaurès -que estima muy especialmente, resaltando su concepción no mecanicista del materialismo-, Rosa Luxemburgo y, más cerca de él, Harold Laski, Carlo Roselli, Fernando de los Ríos, pero también José C. Mariátegui y Raúl Haya de la Torre. Esta suerte de eclecticismo es asumida y reivindicada, cuando afirma que "el socialista encontrará siempre lectura fraterna en aquellas páginas que le refieran la lucha eterna del hombre por la libertad" (1947b: 59). Su bagaje teórico se define, en efecto, por un cierto sincretismo: si no duda en definirse marxista, reivindicando a ambos padres del socialismo científico, otros autores como F. Lassalle tienen lugar en su biblioteca. Su visión del marxismo parece priorizar un corte historicista, donde la obra de Marx aparece como "un poderoso genio polémico frente a la sociedad capitalista". ${ }^{6}$ En todo caso, la doctrina de Marx, asociado siempre estrechamente a Engels, aparece como el fruto de un momento determinado de la historia, por ende, no debe transformarse en dogma y deber ser continuamente renovada de cara a la actualidad. Para Cúneo, "la doctrina valdrá por la exactitud con que se desarrolla y traslada; no por la fidelidad con que se la contempla" (1947b: 53). Pero el trabajo intelectual no tiene autonomía: "sus lecturas serán en el socialista modos de hacer; su doctrina, vehículo, instrumento, arma. Detrás de cada página la acción espera".

Y creía poder ver enmarcada su acción en su reivindicada "generación del 45", llamada a cumplir un rol central en la revolución cuyos prolegómenos imagina en febrero de 1946, posteriormente a la esperada derrota

6. Aunque con fines didácticos, Cúneo aconseja a los jóvenes socialistas iniciar la lectura del opus por La ideología alemana y el Anti-Dühring, antes que El capital. 
definitiva del peronismo. Al lado, pues, de su actividad de publicista, Cúneo desarrolla una activísima militancia partidaria. No por nada es designado, por el voto de los afiliados, candidato a diputado por la Capital Federal en las elecciones de febrero de 1946, una candidatura que se renueva en las elecciones de abril de 1948. Su foto, con su mechón y los inevitables anteojos de carey, se había hecho familiar en la prensa partidaria. Cuando en 1949, con 35 años, pasa a integrar el Comité Ejecutivo Nacional (CEN), todos los observadores están de acuerdo en ver en él uno de los dirigentes con mayor futuro dentro del PS.

En esos años de crisis, Cúneo es el animador de una de las publicaciones más dinámicas de la galaxia socialista de entonces, los Cuadernos de Mañana, que comienzan a editarse en 1950 y que, pese a su corta vida, tenian gran prestigio entre los militantes del PS, en la medida en que reunía a algunos de los intelectuales y dirigentes más prestigiosos del Partido, junto a algunos de los jóvenes más activos, conformando un polo que se ubica a la izquierda de la dirección partidaria. Pero no se aleja de la línea partidaria cuando la táctica es puesta en duda por Julio V. González en el Congreso partidario de 1950. Y es electo nuevamente por los afiliados como candidato a diputado por la Capital Federal, en las elecciones de 1951 por la $11^{\text {a }}$ circunscripción (La Paternal).

\section{El proceso de expulsión}

Estos comicios generales se realizan en un clima enrarecido por la intentona golpista del general Menéndez y un nuevo despuntar del movimiento huelguístico, que lleva al Gobierno a no levantar el estado de excepción. Cúneo, como otros militantes socialistas, es detenido el 30 de septiembre de 1951 y puesto a disposición del PEN en la vieja Penitenciaria Nacional de la avenida Las Heras, tras los coletazos del frustrado movimiento militar. Aunque la mayoría de los presos van siendo liberados, Cúneo continúa detenido. En esas circunstancias su hijo cae gravemente enfermo a fines de ese año, y Cúneo, desesperado, busca los medios para salir en libertad. El partido no avanza en sus gestiones, porque reduce el contacto con el gobierno al mínimo. Ángel Borlenghi, el antiguo socialista devenido un odiado ministro del Interior, alertado por antiguos camaradas, le propone una inmediata libertad, en principio sólo por tres días, lo que le permite dejar su celda el 26 de diciembre. Llegado al final del plazo, y deseándolo prolongar, se entrevista personalmente con Borlenghi, por intermedio del siempre solícito Juan Unamuno. Allí se le informa que no está obligado a volver a la cárcel. Según su relato, Cúneo se decide entonces a gestionar la libertad de los otros socialistas presos, por lo que se dirige, junto con otros cuatro militantes socialistas (según se reconstruye, Julio Gonzá- 
lez Iramain, Luis Ramiconi, Emerio Tenreiro y Jacobo Koffmann), a la Casa Rosada el 2 de enero de 1952 para entrevistarse con el ministro del Interior. Entre dos entrevistas, Borlenghi los termina conduciendo a ver directamente al general Perón. Acto seguido, los dos miembros más prominentes de la delegación, Cúneo y González Iramain, ambos integrantes del Comité Ejecutivo Nacional del PS, piden una reunión de dicha instancia para informar de lo conversado y vagamente acordado. En esa reunión, en la que presentan un memorándum de la entrevista con el presidente, Cúneo critica vigorosamente la ausencia de gestiones para la libertad de los presos. A lo que sigue una agria discusión con N. Repetto, donde se remueven viejas rencillas, pero sin que la disputa tuviera mayor trascendencia pública. ${ }^{7}$

Las cosas comienzan a cambiar cuando González Iramain presenta su renuncia a la máxima instancia partidaria, así como a su condición de afiliado, el 20 de febrero, en carta que se hace pública en la prensa escrita poco después. El CEN parece no querer abrir una crisis, y señala entonces haber archivado los pedidos de expulsión que venían de algunos Centros socialistas. ${ }^{8}$ Pero la conmoción interna del PS se había agravado con la entrevista de Enrique Dickmann con el general Perón el $1^{\circ}$ de febrero de ese año, que había tenido un gran eco en la prensa nacional en la misma tarde en que se produjera. En ese contexto enrarecido, Cúneo hace imprimir a principios de marzo una larga carta, que, con el título "Renuncia al Comité Ejecutivo", no sólo denuncia la inacción del PS ante su caso comparado con otros, sino que pasa a cuestionar la línea partidaria (Cúneo, 1952a). En efecto, el texto se divide claramente en dos partes, cambiando incluso la tipografia de ambas. Luego del pormenorizado relato de los hechos desde su detención hasta la reunión del Comité Ejecutivo, que forman la primera parte, y donde no se ahorran tampoco ataques a las maniobras ghioldistas en torno al proyecto de golpe de Estado del general Menéndez, Cúneo inicia una evaluación crítica de toda la política que se venía llevando a cabo desde la Unión Democrática. Hace pública allí su "disidencia" con las "directivas políticas" del Partido en los últimos años, en particular a partir de 1948, aunque dice no haberla llevado a los congresos partidarios por "solidaridad de cuerpo" con la instancia que integraba. Esto le parecía necesario ahora, porque se estaba luchando ciegamente contra el peronismo, es decir, sin determinar sus causas generadoras. Si había que

7. Ni Cúneo ni González Iramain participan en la reunión del CEN del día 5 de febrero de 1952, que decide presentar al voto de los afiliados la expulsión de Dickmann, signo ya de un alejamiento que no tardaría en estallar. El PS no pide en lo inmediato sanciones para ambos, como lo señalará luego Dickmann.

8. Nuevas Bases, marzo de 1952. 
combatir la demagogia, "no se reparó en que pactar con la vieja infamia para combatir a la nueva, es morir junto a una y otra infamia". El Partido se encerraba en el "chisme" sin presentar un programa socialista para los problemas de la reconstrucción del país.

El antiguo militante del ala izquierda va más lejos y vuelve sobre aquellos años 1930, atacando lo que llama, nunca avaro de imágenes fuertes, el "palo enjabonado de la legalidad justista". En efecto, había que situar en la Década infame las raíces de ese "proceso indiferenciador que hoy neutraliza la función histórica del partido". De cara al presente, habia que retomar el mensaje socialista, renovando un programa que había fijado en la primera posguerra. Y entre los ejemplos más claros no sólo de la inadecuación del posicionamiento, sino de la identificación del PS "con la posición defensiva de la clase conservadora", recuerda la posición reciente de Repetto en defensa del latifundio ganadero en el periódico partidario, y se pregunta si el partido actual no está cercano al viejo PS Independiente de Antonio de Tomaso y Federico Pinedo. Poco después de fechada esta carta, el día 10 de marzo, Cúneo anuncia en nota al CEN su intención de renunciar también a su condición de afiliado, decisión que sin embargo no se concreta.

Los términos de la carta pública (aunque sólo distribuida entre los afiliados) son juzgados gravemente por el Partido, que decide, tras aceptar la renuncia al CEN, "repudiarlos" y pasar los antecedentes del caso a la Comisión de disciplina. Al mismo tiempo, Cúneo, que seguía siendo miembro de la Comisión de prensa, es duramente atacado por Repetto en el número de abril de Nuevas Bases, luego de un altercado entre ambos en la última reunión de la instancia dirigente socialista en que ambos habian participado. Y el CEN decide por resolución del 6 de agosto de 1952 recomendar su expulsión, pasando a organizar el voto general de los afiliados, previsto en los estatutos partidarios, tal como se había hecho con Dickmann en marzo de ese mismo año (Herrera, 2011). La carta de renuncia de Cúneo es interpretada como un "designio de coadyuvar en la campaña difamatoria que se realiza contra el partido", en particular por sus acusaciones veladas contra Ghioldi. En particular, se le achaca alentar la formación de una disidencia, lo que parece confirmado por la edición de un periódico, que con el título de Acción Socialista comienza a aparecer en el mes de mayo. En ese sentido, y luego de reprocharle la incoherencia entre estos juicios retroactivos y su comportamiento partidario en aquellos años de supuesta disidencia, tilda de "desacuerdo conceptual" su posición. Cabe puntualizar que ya adentrado en el conflicto con el CEN, Cúneo no dudaba en calificar al peronismo de "régimen totalitario", un posicionamiento que mantendrá un año más tarde (Cúneo, 1953). Claro que existía un matiz: en 1947 hablaba del totalitarismo como un "enemigo de clase" (1947b: 16). Y 
puesto que la causa generadora del totalitarismo fue el capitalismo, sólo la derrota de éste terminará con aquél (1947b: 20)

Cúneo se debate por evitar el procedimiento, incluso con herramientas legales, pero tras el desarrollo de la votación de los afiliados, el escrutinio tiene lugar el 17 de noviembre. De los 3.942 afiliados (sobre los 6.720 posibles) que toman parte de la votación, una gran mayoría (3.246) aprueban la expulsión y sólo 574 se declaran en contra.

\section{La organización de Acción Socialista}

Como acabamos de ver, entre su renuncia al CEN (marzo) y el inicio del procedimiento de expulsión (agosto), Cúneo decide publicar un nuevo periódico, Acción Socialista, cuyo primer número aparece el 7 mayo de 1952, con una tirada importante (10.000 ejemplares, que se reducen a 6.500 a partir del tercer número). Como razón principal aduce la imposibilidad de publicar en el periódico oficial mientras dura el trámite ante la Comisión de disciplina, tal como había sido decidido por el CEN, y que le impedía contestar a las acusaciones. Es así que el primer número incluye la larga réplica a la carta de Repetto. Según su propia confesión, los primeros números del periódico son integramente escritos por Cúneo, con la módica ayuda de su esposa, y aunque pronto se abrirá a nuevas colaboraciones de sus allegados y amigos, será siempre él el redactor principal. En sus inicios, el ritmo del periódico es muy activo, ya que sale por entonces quincenalmente. ${ }^{9}$

Es con la publicación del "Testamento político de Mario Bravo" que el periódico se daba a conocer públicamente en su primer número, todavía muy orientado a sus compañeros socialistas. Una frase del texto de Bravo parece resumir el anhelo de Cúneo en su nuevo posicionamiento: "La sociedad no vendrá hacia nosotros porque nos ignora; pero nosotros iremos a la sociedad porque la conocemos".

Uno de los editoriales más significativos de esta fase es aquel aparecido en el número 3, del 4 de junio de 1952. El texto se llama "La 'contra', el gobierno y el socialismo". La "contra" aparece como un tipo de oposición, en el cual se engloba al PS, que permanece en el propio universo peronista, aunque más no sea negativamente. Es por ello que no tiene un programa superador del peronismo. Se necesita, en cambio, una crítica que no se pierda en la "intriga estéril", que tenga perspectivas, y éstas no pueden ser más que socialistas. Pero "el socialismo sólo puede

9. Rápidamente su edición comienza a espaciarse: el $\mathrm{N}^{\circ} 5$ es de julio; el $\mathrm{N}^{\circ} 6$, de octubre; el 7, de diciembre de ese año; el 8, de febrero de 1953; el 9, de abril; el 10, de junio; el $11 \ldots$, de octubre; el 12, de diciembre; el 13, de marzo de 1954; el 14, de junio, y el 15 , recién de marzo de 1955, aunque, como veremos, un conjunto de importantes vicisitudes internas explican los diez meses que separan estos números. 
ser pensado en términos de revolución", lo que marca los límites con el viejo partido. Y después de aseverar que se trata de un largo proceso, expresa su confianza en la acción de la clase trabajadora.

En momentos en que el CEN sospecha de la intención de crear una tendencia, Cúneo parece anunciar también el tipo de estrategia que desplegará por fuera del PS. Afirma en efecto que el posicionamiento socialista no implica una identificación partidaria, implica una acción que va más allá de esa esfera. Sin embargo en la carta que dirige al CEN tres días más tarde, el 7 de junio de 1952, Cúneo asegura que se trata de una publicación "al servicio de las ideas, el método y la orientación del Partido Socialista”. Y para despejar dudas sobre un supuesto apoyo oficial a su iniciativa, detalla en la misma el modo en que financia la publicación, que se imprime en una imprenta de la que él es socio.

Con el correr de sus números, ya separado definitivamente del PS, el periódico deja entrever una visión del socialismo menos liberal, más latinoamericana, más claramente apegada a un programa de socialización de los medios de producción, o al menos a la planificación. En ese sentido, busca identificar su perfil con la figura de Alfredo Palacios, cuyas fotos son omnipresentes en los primeros números, y al que se termina dedicando un amplio reportaje en el número 8 de 1953. Llama así desde sus páginas a nacionalizar la CADE, los frigoríficos, el petróleo, proponiendo asimismo la colectivización de la tierra y el desarrollo de la planificación. Como se afirma más tarde desde esas mismas columnas, cuando se consolida la idea de crear un nuevo grupo, la liberación nacional será socialista, y en ese sentido el socialismo es la Nación.

Los editoriales del periódico mostrarán además una posición más abierta hacia el peronismo, que se distingue claramente de la cerrada oposición del PS, y que Cúneo condensa en una frase de su elegante prosa: "La multitud argentina trae en su resentimiento una versión primaria, pero en un todo verídica, de los grandes problemas argentinos". Había que transformar ese anhelo de justicia económica en conciencia de clase, en instrumento de su propia emancipación, y de liberación de la nación. Como escribía en ese texto de diciembre de 1952, "la multitud argentina está en la calle. Con ella, nuestra esperanza”. Poco después, en un texto cuasi programático de junio de 1953, se lee en Acción Socialista: "En el camino andado en derechos populares, hacia atrás ni un paso". Pero "queremos dar muchos pasos más hacia adelante". Se trata, en definitiva, de "una oposición al actual régimen sostenida con sentido de futuro". Pese a su identidad socialista, no duda en avanzar el concepto de "comunidad nacional" o "movimiento nacional".

El análisis del peronismo recibirá un mayor espesor cuando el periódico cumpla sus dos años de vida. La anatomía pone el acento en su elasticidad, su agilidad, pero también los "escasos compromisos ideoló- 
gicos" que habían marcado su rápido despliegue en la escena nacional. Aunque, a diferencia del PS, se reconocen las ventajas inmediatas y efectivas para los trabajadores, se trata de un "despliegue demagógico", en un marco autoritario de supresión de las grandes libertades, en particular el derecho de huelga. En ese sentido, el peronismo tiene una doble función: por un lado canaliza el descontento de las masas pero por el otro las neutraliza, en momentos en que, finalizada la Segunda Guerra Mundial, éstas se aprestaban a lanzar el ataque contra el régimen burgués. Pero "cumplidas sus promesas mínimas, su insuficiencia programática le augura caminos de retorno". En ese sentido es "un episodio transicional", entre el país del pasado y el del futuro, haciendo mucho más explícita que el grupo de Unamuno su distancia con el peronismo. De hecho, las contradicciones que la integran comienzan a actuar con autonomía. Pero concluye diciendo que "entenderemos que si la clase trabajadora peronista ha de permanecer enrolada en el movimiento, debe persuadirse sólo por la elocuencia de los hechos". ${ }^{10}$

Para entonces, y después de un año consagrado a la publicación del periódico, en septiembre de 1953, Cúneo y sus seguidores deciden constituirse en agrupación, siempre con el nombre de Acción Socialista. Junto a él, encontramos a Jorge E. Felizia, Marcos Merchensky, Manuel G. García, Francisco Madrazo, que a partir del séptimo número aparecían como miembros del comité editor de la prensa, a los que se suman Ernesto Janín, Giordano Bruno Tasca, Eduardo Rocca, Hector Alberto Chaponick, Jorge Godoy Ortiz, Abel A. Méndez, Nicolás F. Ciliberti, Ricardo F. Britos. Asimismo, Acción Socialista reivindica como sus presos a Walter M. Pontalti, Aldo Toustian, Alberto López Dabat, Rosin y el ya mencionado Ciliberti. ${ }^{11}$

Manuel G. García, que había sido un dirigente de la FUBA, figura como el secretario general. El nuevo agrupamiento lanza en ese momento una campaña financiera, y abre un local público en Humberto I ${ }^{\circ} 1175$. A partir de ese mes de septiembre de 1953 comienza también a editar un boletín. En él afirman claramente las coordenadas de la nueva organización: "Somos socialistas de ayer, de hoy y de mañana". El modo de funcionamiento sigue la óptica que venía adoptando el periódico; proponen asi una serie de "seminarios de estudios", sobre la actualización del Manifiesto comunista de acuerdo a la realidad latinoamericana (Tasca y Méndez), los órganos económicos de la revolución (García), e incluso los órganos jurídicos de la revolución (Rocca). En esos momentos,

10. Acción Socialista, $\mathrm{n}^{\circ} 14$, junio de 1954.

11. Sobre los miembros de Acción Socialista obtuve valiosa información en una entrevista con Arnoldo Belmes (agosto de 2010) y un posterior correo electrónico (junio de 2013). 
la agrupación defiende la posibilidad de pertenecer simultáneamente a Acción Socialista y al PS, ya que aquella no se propone ser un partido politico.

$\mathrm{Y}$ en efecto, distinguirse del viejo partido por su accionar no era la única preocupación de Cúneo: también busca separase del PSRN, que se había organizado a partir de 1953 (y donde habian ido a parar algunos de quienes lo habian sostenido en el conflicto interno de 1952). En efecto, para Cúneo lo que oponía a ambos sectores era lo calificaba como "lucha de facciones". Unos actuaban dentro del radio del peronismo, mientras que los otros lo hacian dentro del radio de la oligarquía. ${ }^{12}$ En varias ocasiones, Cúneo habia tratado despectivamente a quienes buscaban acercarse al Gobierno, pero, por cierto, el PS no hacía distingos y el Consejo Nacional calificaba a Acción Socialista como "otra manifestación de la misma subversión política, tendida hacia la finalidad de destruir el partido como fuerza política autónoma y libre". ${ }^{13}$

Un documento de enero de 1954, Acción Socialista y la realidad argentina, fija la posición general de la nueva organización. Adentrado en la construcción de su propia identidad, el grupo trata ahora de poner distancia con el viejo PS, al menos de cara al futuro. Se ve a Acción Socialista como el "núcleo promotor de una activa vanguardia socialista". La lucidez no les impide sin embargo aceptar que su llamado no tiene por destinatario a las grandes masas, sino que se dirige a formar equipos para estudiar los grandes problemas. Y puestos a discutir de teoría, reivindica como "su método de investigación histórica" al marxismo, aunque dice aceptar todo otro que tenga como meta el socialismo. Este documento, sin duda el más importante que produce el grupo, será la base de su "Declaración de propósitos", que da junto con sus estatutos. Su lema es: "La Nación será libre por el socialismo".

El periódico oficial del PS se hace eco, para denostarlo, de este intento de crear una nueva organización. No se trataria de un partido de ciudadanos, sino de agrupaciones sindicales, culturales, cooperativas, centros de estudios según el modelo del laborismo británico, aunque señala que los promotores se contentan por ahora con un centro de estudios del tipo de la Sociedad Fabiana, que tendría, entre otras funciones, la de preparar los planes de gobierno cuando se produjera el fin del peronismo. Frente a ello, el periódico ataca su falta de compromiso en la lucha frontal que exige un gobierno totalitario. ${ }^{14}$

Ya en su lógica organizativa un tanto ambigua, la agrupación fijará posición con respecto a las elecciones de abril de 1954, sin presentar

12. Esto es, 2 de marzo de 1954.

13. Nuevas Bases, septiembre de 1953.

14. Nuevas Bases, 20 de febrero de 1954. 
ni apoyar candidatos, ya que la clase trabajadora no podrá sentirse representada por ninguna de las fuerzas en pugna, al menos mientras peronistas y antiperonistas defiendan la propiedad privada de los medios de producción y de cambio. Pero la declaración deja entrever en paso más hacia una formación más ambiciosa: se dice allí que hay lugar para un partido que dé respuesta a la clase trabajadora en sus reivindicaciones sociales, y al pueblo entero en la emancipación de América. En otras palabras, comienza a instalarse la idea de que, a más de una sociedad de estudios, el grupo podia dar a luz un partido, cuyo programa impulsará la reforma agraria, la democracia industrial y la independencia nacional.

La acción propagandística, a cargo de Cúneo, es en todo caso siempre muy activa y en ese mismo mes de abril se suma al periódico unos "Cuadernillos de divulgación internacional", que muestra mucho interés por la acción de Nehru -la India era, junto con China, uno de los modelos en que Cúneo cifra su esperanza ya en los años 1940-, pero también, con ese eclecticismo que ya hemos señalado en Cúneo, el POUM, y que se repite en septiembre. Entre ambos, había tenido lugar el primer congreso de Acción Socialista, en julio de 1954.

Aunque Cúneo sigue definiendo Acción Socialista como "una agrupación de estudios argentinos", la actividad desplegada empieza a ser más importante y no se reduce a meros seminarios. En todo caso, un boletín de agosto de 1954 da cuenta de actividades en Bahía Blanca (que constituye la "Federación Regional del Sur"), Tucumán, Mendoza, Entre Ríos, Santa Fe, Córdoba y en varias localidades del conurbano bonaerense (Quilmes, Bernal, Berazategui). Estos núcleos pueden editar su propia prensa, como Avanzada, en Mendoza, o Militancia en la Regional sur.

Si aún a principios de 1955 se ven todavía como un "fermentario principista", en marzo de ese año se produce el dubitativo salto: el grupo decide organizarse como partido, adoptando el nombre de Liga Socialista Popular. La creación de este nuevo agrupamiento, más ambicioso, tendría una causa principal, según se aduce en su prensa: el aumento de sus adherentes que impediria continuar con el antiguo funcionamiento. Acción Socialista había sido creada para el estudio y el debate, pero no cabía en ella la urgencia de la militancia y el proselitismo. Cúneo y su grupo anuncian asi un cambio de perspectiva, porque se considera ahora un partido, "el gran partido de la clase trabajadora". Su núcleo central, se declara, es el de Acción Socialista y García pasa a ser el secretario general de la nueva organización.

El nombre del nuevo partido, y en particular el epíteto "popular", "indica que nuestra confianza radica en el pueblo, que no desconfiamos de él, ni aspiramos a tenderle una trampa demagógica", reivindicando un 
calificativo que ya ha sido agregado por los partidos chileno y colombiano. Busca así diferenciarse de las que denomina "formas fraudulentas" de socialismo, encarnadas tanto por el del viejo partido como por aquel inconducente y torpe oportunismo que pacta con el actual régimen. Con todo, reivindica las "mejores tradiciones del socialismo argentino", pero "enriquecidas con un nuevo pensamiento crítico, remozadas por la energia combatiente de nuevas promociones militantes para dotar a la clase trabajadora del país de un gran movimiento de liberación nacional".

Para asegurar la coherencia con el viejo proyecto de grupo de estudios, se reproducen un conjunto de extractos de los números anteriores del periódico bajo el título "principios de orientación para el socialismo argentino", donde la clase trabajadora aparece como el principal agente de la liberación nacional. Entre otras precisiones organizativas, se anuncia la aparición de un "Cuaderno de acción socialista", que será la tribuna de doctrina. La prensa nacional se hace eco de la agrupación, y señala entre sus miembros, aparte de los hombres ya conocidos (Cúneo, Merchensky, García, Méndez), a Emerio Tenreiro Anaya, Jorge A. Chinetti y Juan O. Taire. Alguna nota periodística alienta el accionar del grupo, con la idea de crear "un Partido socialista con raigambre popular", dándole sin duda una significación mayor que la extensión real del grupo. ${ }^{15}$ En todo caso, los documentos internos presentan el punto de vista de la Liga como "sereno, sensato, argentino y socialista". En el clima de crisis que llevará poco después al derrocamiento del general Perón, el nuevo partido toma posición en favor de la separación de la Iglesia y el Estado, ante una posible reforma de la Constitución. A escala internacional, el grupo parece ilusionarse con una tercera vía a la yugoslava, como lo consagra una nota de julio de 1955, aunque también se sigue siempre con interés la experiencia del gobierno del Partido del Congreso en India.

La transformación en partido no parece haberse hecho sin disidencias internas. Ya en su propia proclamación, la Liga toma distancias explícitas con el filobolchevismo y el "trotsquismo encubierto", que sin duda veía en algunos sectores del PSRN. Incluso, algunos miembros del grupo original (Felizia y Eduardo Rona) se alejan con una postura que se denuncia como pro-soviética. En realidad, las fisuras habian tocado a otros miembros del grupo fundador...

Es así que en el número 17 del periódico, que aparece en agosto de 1955 con un nuevo formato, se señala que Cúneo, García, Merchensky y Méndez se han desvinculado de Acción Socialista, retrotrayendo su

15. El espacio que se le da a Cúneo, y que parece exagerado teniendo en cuenta la debilidad de su grupo, se explica sin duda por el hecho de que es en esos momentos redactor de Esto Es, un cargo que ocupará hasta 1956. 
salida a diciembre de $1954 .{ }^{16}$ En un acto público que se lleva a cabo el 26 de agosto de ese 1955 en el local de Humberto $I^{\circ}$, bajo el tema "Acción Socialista y la convivencia", ocupan la tribuna Ernesto Weisz, Ernesto Janín, Eduardo Rocca y un joven estudiante, Guillermo Estevez Boero. El grupo repudia, en particular, la intentona golpista del 16 de junio pasado, denunciando que lo preparaba la reacción clerical. Todavía habrá tiempo para una última aparición del periódico, en manos del grupo disidente, en noviembre de 1955. En él hacen pública una declaración adoptada en un plenario del 15 y 16 de octubre, donde sostienen que "el derrumbe del régimen peronista es un paso positivo", en la medida que restituye libertades. Pero al mismo tiempo que rechaza a los burócratas de la CGT peronista denuncia al supuesto movimiento sindical libre, declarándose en definitiva contrarios a la división del movimiento obrero (la primera página del periódico se abre con la consigna "El obrero que divide la organización sindical traiciona a su clase"). Se reclama, además, un aumento de salarios y el congelamiento de precios. En un "Mensaje a los trabajadores", subrayan haber enfrentado a Perón -que cayó por haber defraudado a la clase- sin comprometerse con los caducos partidos tradicionales, $\mathrm{y}$, tras reivindicar el socialismo revolucionario, llama a constituir el partido de los trabajadores. ${ }^{17}$

Por su parte, Cúneo continúa reivindicando, ya con la Revolución Libertadora en el poder, el proyecto de construir un socialismo renovado bajo el amparo de la Liga Socialista Popular. Tras calificar a Perón de demagogo y no de revolucionario -"con la verdad del socialismo hizo su mentira demagógica"-, achaca a las viejas formaciones, que disociaron conceptos y realidad, y concluye llamando a una nueva organización a partir de la federación de organismos económicos, culturales, técnicos y políticos. Aunque ya este renovado intento de reproducir una lógica laborista no tendrá mayor eco, no termina aquí la historia de Acción Socialista, o al menos la de su principal inspirador.

En febrero de 1958, ya con otro formato y en dos colores, reencontramos una nueva Acción Socialista, sin duda con un intento de reno-

16. Ha sido por el momento imposible de reconstruir con exactitud lo ocurrido, aunque puede analizarse como hipótesis que una parte del grupo avanza hacia la construcción de la Liga Socialista Popular, y otro prefiere conservar el formato de Acción Socialista. En todo caso, el contenido del $\mathrm{N}^{\mathrm{o}} 16$ de Acción Socialista, de junio de 1955, se presenta como órgano de la Liga Socialista Popular y es redactado por los hombres cercanos a Cúneo.

17. Un plenario nacional de la agrupación, reunido el 15 y 16 de octubre de 1955 , bajo la dirección de Héctor Mosches y el abogado Juan C. Deghi, llama a intensificar la acción en pos de la creación del partido de los trabajadores. El grupo terminará por crear un efimero Partido de los Trabajadores, que se presenta a las elecciones constituyentes de 1957, obteniendo un convencional en la persona de Deghi. 
var la vieja prédica, buscando inscribirse en una continuidad: aparece como un erróneo número 16 y retoma algunos de los editoriales de su primera época. Se sigue reivindicando en términos de vanguardia socialista, para "la configuración de la Nación como tal y la liberación de sus clases trabajadoras". En ese sentido se habla de la coincidencia entre los problemas de la Nación y los de la clase trabajadora. Si se conserva la prédica latinoamericanista, la palabra "desarrollo" es omnipresente, por cierto, en relación a la independencia del subcontinente. Aparte de los nombres ya conocidos de Méndez, Rosín, Godoy Ortiz, Ciliberti y Madrazo, encontramos ahora el de Antonio Brizzi, siempre encabezado por Cúneo, que reaparece nuevamente sin ambages como el director de la publicación.

Pero para esa fecha, Cúneo y sus hombres (entre ellos, su gran amigo Merchensky o aún Manuel García) se habían acercado al candidato presidencial de la UCRI, Arturo Frondizi. Si muchos viejos militantes de izquierda no eran ajenos a este apoyo, concebido en clave de frente nacional y popular, Cúneo parece dar un paso más, pasando a integrar algunos de los equipos del candidato radical intransigente, por el cual sentía una antigua simpatía, ${ }^{18}$ siendo en particular miembro de la redacción de la revista Qué, encabezada por Rogelio Frigerio.

\section{Conclusiones}

En su momento de mayor ambición, Cúneo parece imaginar el partido de la clase obrera de la nueva Argentina con los rasgos del laborismo británico, que aparece así como posible tercera vía entre el PS y el peronismo, conjeturando de ese modo que el contacto con el nuevo movimiento sindical que este último había generado permitiria la renovación de las prácticas de aquél. En ese marco, definía un lugar propio de intervención. El modelo de intelectual como partido -es decir una organización que hace de la tarea intelectual su modo de acción política-, que su grupo pretendía encarnar, podía coadyuvar en la constitución de esa nueva organización, buscando reproducir de algún modo la historia de la Sociedad Fabiana.

Sin embargo, no se abandona a lo largo de la experiencia de Acción Socialista una cierta ambigüedad para definir su accionar, ya sea como un fermentario o bajo la forma partido, como se termina dando el paso a partir de cierto momento. Esta ambigüedad táctica es probablemente fruto también de la debilidad del grupo. Se debe notar además, que a

18. Que ya se había expresado, incluso desde las columnas de Acción Socialista, por Moisés Lebenshon, al que consideraba su amigo (entrevista con Dardo Cúneo, agosto de 2003). 
diferencia de otros grupos que alentaban ambiciones próximas, como el Instituto de Estudios Económicos y Sociales que orientan antiguos afiliados socialistas capitaneados por Juan Unamuno, Acción Socialista se mostrará menos proclive a producir un saber técnico en torno a algunos de los problemas económicos de entonces, en parte porque no pretende influir concretamente en las reparticiones oficiales (Herrera, 2009), y en parte por el propio perfil literario de Cúneo. Tentados, como el grupo de Unamuno, a organizarse como partido político, carecerán sin embargo de una figura pública como Enrique Dickmann para poder alentar ambiciones mayores. ${ }^{19}$

Si la experiencia de Acción Socialista no dejará mayores rastros, cabe notar que ninguna de las disidencias socialistas que emergen bajo el peronismo logra dar nacimiento a una organización estable. El intento más ambicioso, este PSRN, comienza a resquebrajarse luego del estrepitoso fracaso electoral de 1954 y no logra dar vida después de esa fecha a un proyecto ideológico y organizativo coherente (Herrera, 2011). Aun reducido a un número de adherentes muy bajo (la cifra se puede reconstruir en torno a los 7.000 afiliados), las bases socialistas parecen mostrarse fieles a las consignas de la dirección en esa primera mitad de los años 1950, aunque más no sea por considerar que el viejo Partido, y el país todo, están viviendo una situación de excepción. Prueba de ello es el hecho que las antiguas disidencias internas estallan definitivamente en 1958, ya en un marco de relativa normalidad. A la larga, esto da a entender a su vez un alto nivel de aceptación por parte de los afiliados con las caracterizaciones que se están haciendo por entonces del peronismo como fenómeno totalitario.

Como orientador de la experiencia de Acción Socialista, se destaca en Cúneo una nueva lectura del rol de un partido socialista en la lucha por la liberación nacional. Esta visión, que tiene sus raíces en las experiencias disidentes del socialismo de los años 1930 pero encauza con otros discursos políticos más amplios, permite al grupo activar ciertos conceptos, donde sobresale, por la posteridad que tendrá ya bajo la experiencia desarrollista, el de "movimiento nacional".

Con todo, quizás se pueda identificar un legado político de Acción Socialista en las vicisitudes ulteriores de la organización socialista, en las que tendrá un rol activo uno de esos jóvenes que realizan sus primeras experiencias con Cúneo, aquel promisorio estudiante de la Universidad Nacional del Litoral que se había incorporado a mediados de 1954 llamado Estévez Boero. Aunque su acción partidaria, prolongada

19. Sobre todo, no debe soslayarse la diferencia de fondo que los distingue en un plano doctrinal: Acción Socialista se muestra explícitamente ajena a una reivindicada "Revolución Nacional" encarnada por el Gobierno del general Perón, y mucho más al universo peronista que el PSRN reivindicaba. 
en el Partido de los Trabajadores, deja poca huella por entonces, pronto se destacará como dirigente universitario, llegando a presidir en 1959 la Federación Universitaria Argentina. Cuando, algunos lustros más tarde, en 1972, Estévez Boero haga confluir su propio grupo político -el Movimiento de Acción Popular Argentino (MAPA), creado a partir de una agrupación estudiantil- en una de las repetidas tentativas por refundar un partido socialista reunificado, muchas de las prédicas del antiguo fermentario, e incluso ciertos modos de funcionamiento a partir de grupos de "estudio" de la realidad, se encontrarán en la concepción que pretende expandir. Empezando por el nombre de "socialismo popular", que, como vimos, habia reivindicado como signo distintivo el grupo de Cúneo en marzo de 1955.

Cúneo, tras un corto paso en la función pública en el Gobierno de Frondizi -primero como Secretario de Prensa de la Presidencia de la Nación y, luego de abandonar dicho cargo en 1959, como representante argentino ante el Consejo de la OEA-, no retomará la acción militante. Y es cerrada ya su actividad política que encontramos la obra más ambiciosa de Cúneo en el campo de las ciencias sociales. Se trata de una historia social de la clase dirigente, aparecida en 1967 con el título Comportamiento y crisis de la clase empresaria. El libro puede ser considerado como un estudio pionero de los análisis de la clase dominante que ilustrarán más tarde los trabajos de Jorge Federico Sábato o Jorge Schvarzer. La obra no hace explícita su inscripción política y busca inscribirse en las ciencias sociales. De hecho, Cúneo abandona en este libro, salvo en los párrafos finales, su personal estilo, para adoptar una escritura académica, neutra. En el fondo, algunas de las tesis de su conclusión habian sido ya avanzadas por Milcíades Peña, como el carácter especulativo de la burguesía (1967: 280), o ya circulan desde hace tiempo, como la dominación hegemónica de la SRA sobre la UIA. Pero interesa marcar aquí apenas las evoluciones del pensamiento de Cúneo, empezando por una revaloración del peronismo, que ahora aparece como un movimiento de masas (1967: 279). Detrás de la defensa de la CGE y su tesis que afirma que "la pequeña y mediana industria comparece, en nuestros días, como la aliada política del Estado argentino en la definición de objetivos de expansión territorial hacia adentro, de soberanía hacia afuera y de modernidad en criterios y metodología propias de la época" (1967: 282), adivinamos ya el posicionamiento desarrollista de Cúneo -no por nada habla de "certidumbre de desarrollo nacional"-.

Un párrafo condensa su nuevo credo:

La sociedad moderna a la que aspiramos, debemos y podemos ser se logrará a partir de la explotación racional y reproductiva de nuestra riqueza con las técnicas más avanzadas 
de nuestros días, asegurando una distribución de bienestar en coincidencia con los esfuerzos realizados para lograrlo y promoviendo oportunidades de realización para todas las vocaciones personales. (1967: 284)

Si su interés por la clase media, expresado ya en los años 1950, podía servir de puente para su nueva posición, el socialismo, en cambio, desaparece de su horizonte, reemplazado, en el mejor de los casos, por un llamado a la distribución del bienestar (1967: 284). Cúneo ha ganado con esta obra su autonomía de intelectual pero a costas de perder su identidad como socialista.

\section{Bibliografia}

Cole, M. (1961), The Story of Fabian Socialism, Stanford University Press. Cúneo, D. (1943), Juan B. Justo, Buenos Aires: Americalee.

- (1947a), Juan B. Justo y la Declaración de principios del Partido Socialista,

Buenos Aires: La Vanguardia.

- (1947b), El militante, t. II, Buenos Aires.

- (1950), El militante, t. III, Buenos Aires: La Vanguardia.

- (1952a), Renuncia al Comité Ejecutivo, Buenos Aires.

- (1952b), Cuaderno de milicia, Buenos Aires: Logos.

- (1953), El delito de opinión y el CE del P. Socialista, Buenos Aires.

- (1967), Comportamiento y crisis de la clase empresaria, Buenos Aires: Pleamar.

Ghioldi, A. (1947), "Prólogo" a J.B. Justo, La realización del socialismo, Obras de Juan B. Justo, t. VI, Buenos Aires: La Vanguardia.

Graciano, O. (2008), Entre la torre de marfil y el compromiso. Intelectuales de izquierda en la Argentina, 1915-1955, Bernal: Universidad Nacional de Quilmes.

Herrera, C.M. (2003), "El Partido Socialista ante el peronismo, 1950. E1 debate González-Ghioldi”, Taller. Revista de sociedad, cultura y política, Buenos Aires, No 21, pp. 116-137.

- (2005), “¿La hipótesis de Ghioldi? El socialismo y la caracterización del peronismo, 1943-1956", en H. Camarero y C. M. Herrera (eds.), El Partido Socialista en Argentina: sociedad, politica e ideas a través de un siglo, Buenos Aires: Prometeo, pp. 343-366.

- (2006), "Corrientes de izquierda en el socialismo argentino (1932-1954)",

Nuevo Topo. Revista de historia y pensamiento crítico, Buenos Aires, $\mathrm{N}^{\circ}$ 2, abril, pp. 127-153.

- (2007), Las huellas del futuro. Breve historia del Partido Socialista en Argentina, Buenos Aires: La Vanguardia.

- (2009), "Socialismo y revolución nacional en el primer peronismo. El Insti- 
tuto de Estudios Económicos y Sociales", Estudios Interdisciplinarios de América Latina y el Caribe, Tel Aviv University, vol. 20, 2, pp. 89-114. - (2011), "El Partido Socialista de la Revolución Nacional: la realidad y su mito", Revista Socialista, Buenos Aires, No 5, 2011, pp. 85-114, retomado en C.M. Herrera (ed.), La "crisis peronista" del Partido Socialista, historiapolitica.com [en línea en febrero de 2012].

Pease, E. (1916), The History of Fabian Society, Nueva York: Dutton. Repetto, N. (1943), en Cúneo (1943).

$$
* * *
$$

Resumen: Este trabajo se propone analizar la experiencia política que encabezara Dardo Cúneo (1914-2011) durante el segundo gobierno de Perón. Activo organizador de las actividades intelectuales del PS, admirado por su pluma y considerado como una de las jóvenes promesas del Partido, es sin embargo expulsado a fines de 1952, tras fundar un nuevo periódico, Cúneo se consagrará poco después a la organización de un grupo, Acción Socialista. Inspirándose en la Sociedad Fabiana, es como centro de estudios que busca influir en la acción y en el programa del socialismo. La experiencia fracasará rápidamente, cuando el grupo intentará transformarse en partido, pero representa en esos años uno de los intentos más originales de dar respuesta a la cuestión de una fuerza alternativa de izquierda, sin reproducir la forma partido.

Palabras clave: Socialismo - Dardo Cúneo - Intelectuales - Peronismo

Abstract: This work proposes an analysis of the political experience lead by Dardo Cúneo (1914-2011) during the second Peron government. Active organizer of the socialist party's cultural and press activities, praised as a writer and considered as one the young promises of the Party, he is however expelled in late 1952 after he created a new journal. Cúneo then dedicate himself to the organization of a political group, Accion Socialista. Inspired by the Fabian Society, is as a research center that seeks to influence the socialist action and program. The experience quickly fail when the group will try to become party, but in those years represents one of the most original attempts to answer the question of an alternative force left without taking the party form.

Keywords: Socialism - Dardo Cúneo - Intellectuals - Peronism

Recepción: 6 de marzo de 2013. Aprobación: 10 de agosto de 2013. 